\title{
How Prior Programming Experience Affects Students' Pair Programming Experiences and Outcomes
}

\author{
Nicholas A. Bowman \\ nick-bowman@uiowa.edu \\ Educational Policy \& Leadership Studies \\ The University of Iowa \\ Iowa City, Iowa \\ $\mathrm{KC}$ Culver \\ kc-culver@uiowa.edu \\ Educational Policy \& Leadership Studies \\ The University of Iowa \\ Iowa City, Iowa
}

\author{
Lindsay Jarratt \\ lindsay-jarratt@uiowa.edu \\ Educational Policy \& Leadership Studies \\ The University of Iowa \\ Iowa City, Iowa \\ Alberto Maria Segre \\ alberto-segre@uiowa.edu \\ Computer Science \\ The University of Iowa \\ Iowa City, Iowa
}

\begin{abstract}
Pair programming is a collaborative learning approach in computer science in which students (or employees) work closely with a partner on the same programming task. A long-standing question within pair programming is whether certain combinations of students lead to greater learning, effort, and/or performance. Earlier studies have explored the role of prior programming experience, including the discrepancy between partners' experience, as a potentially important factor in shaping these outcomes. However, the previous findings are highly inconsistent, which may result from divergent (and often suboptimal) ways of defining previous experience or skill, problems with self-selection into pairs, and small sample sizes that often yield nonsignificant results. The present study sought to improve on all of these limitations through an examination of 587 undergraduates who each participated in three different randomly assigned pairings. Not surprisingly, students' own programming experience was positively related to understanding concepts from lab, confidence in the finished product, and overall interest in computer science. However, students who worked with a more experienced partner actually had poorer outcomes, including lower effort exerted on the assignment, perceptions that their partner gave more effort than they did, less time in the driving role (i.e., typing out the assignment), lower understanding of concepts from lab, and less interest in computer science overall. The partner's experience is unrelated to other outcomes, including confidence in the finished assignment, feeling productive
\end{abstract}

Permission to make digital or hard copies of all or part of this work for personal or classroom use is granted without fee provided that copies are not made or distributed for profit or commercial advantage and that copies bear this notice and the full citation on the first page. Copyrights for components of this work owned by others than the author(s) must be honored. Abstracting with credit is permitted. To copy otherwise, or republish, to post on servers or to redistribute to lists, requires prior specific permission and/or a fee. Request permissions from permissions@acm.org.

ITiCSE '19, July 15-17, 2019, Aberdeen, Scotland UK

(C) 2019 Copyright held by the owner/author(s). Publication rights licensed to ACM.

ACM ISBN 978-1-4503-6301-3/19/07 . .\$15.00

https://doi.org/10.1145/3304221.3319781 during lab session, and average grades received during the pairing. These results provide important considerations for the assignment of students to pairs.

\section{CCS CONCEPTS}

- Social and professional topics $\rightarrow$ CS1.

\section{KEYWORDS}

Pair programming; pair characteristics; pair incompatibility; programming experience; computer science; collaborative learning; college students; university students; student outcomes; experimental research; randomized controlled trial.

\section{ACM Reference Format:}

Nicholas A. Bowman, Lindsay Jarratt, KC Culver, and Alberto Maria Segre. 2019. How Prior Programming Experience Affects Students' Pair Programming Experiences and Outcomes. In Innovation and Technology in Computer Science Education (ITiCSE '19), July 15-17, 2019, Aberdeen, Scotland UK. ACM, New York, NY, USA, 6 pages. https://doi.org/10.1145/3304221.3319781

\section{INTRODUCTION}

Popularized by proponents of agile programming methods [2], pair programming has become increasingly prevalent in both industry and classroom settings as an efficient, effective, and enjoyable method for producing code (for reviews, see $[11,12,15,32,35])$. Scholarship has often found that the implementation of pair programming leads to increased coding output, improved product quality, reduction of errors, and greater programmer enjoyment $[3,15,16,18,24,26,27$, $37,38,40]$. However, despite the wealth of evidence suggesting the benefits of pair programming, it can also sometimes lead to ineffective, irritating, and exhausting interactions if partners are not compatible [7].

This large-scale experimental study explores the effects of individual programming experience and pair composition on students' confidence, lab attendance, understanding of concepts, effort, and productivity, as well as perceptions of a partner's effort. Results of previous studies on this topic have been mixed; while scholars generally agree that prior 
experience matters for pair compatibility and outcomes of pair programming, there is minimal agreement on how it matters and under what conditions. This study supports recommendations that students with similar skill levels be matched together, and it adds nuance by illustrating the negative effects of pairing less experienced students with more experienced partners.

The remainder of this paper is organized as follows: Section 2 provides a summary of literature on the relationship between student experience and pair programming outcomes and satisfaction. Section 3 introduces our study and describes our research methods and analysis procedures. In Section 4, we share our results, followed by a discussion of our findings in Section 5 and possibilities for future research in Section 6 .

\section{PREVIOUS RESEARCH}

The existing literature has explored how students' prior experience and ability might influence their perceptions of pair programming, but the findings are highly inconsistent. For example, some scholars have found that stronger or more confident coders are more likely to enjoy pair programming [14], while others have found the opposite to be true [21, 34], and still others have found no relationship [23]. This disagreement may be due to wide variation in how skill and confidence are measured as well as divergent protocols for matching students.

More tangibly, the observed behaviors of veteran and novice programmers differ in pair programming situations. For example, more expert programmers average fewer interactions per hour, while novice programmers spend twice as much time suggesting and counter-suggesting [5]. Additionally, less-skilled programmers are more likely to have or perceive increased efficiency with pair programming, while more skilled programmers are more likely to become frustrated by challenges that arise in pair programming situations [7]. Plonka et al. [29] observed that novice programmers are at risk of disengagement, particularly when serving in the navigator role. Building on this observation, a subsequent study examining knowledge transfer in pair programming observed more expert partners struggling to balance the cognitive load of simultaneously thinking through code and explaining concepts to more novice partners [30].

Although personality mismatch is often cited as a reason for poor pair programming experiences and outcomes, it has only modest predictive power when compared with expertise and task complexity [17]. Differences in the relative skill of partners is one of the most consistently offered explanations for poor pair outcomes, but there is little agreement on how best to pair programmers. Some researchers have asserted that instructors should avoid pairing programmers with a wide disparity in ability and experience $[4,6,7,10,20,33,36$, 39], but how much variation in skills is desirable or acceptable is less clear. Oya and Uchida [28] found that the best pairs had a small difference in academic ability but a large difference in experience with computers, and Van Toll et al. [36] observed the most positive learning environments when one partner had slightly more experience than the other without letting the gap be too large. Another large-scale study found that pairing by skill level was important for graduate students, but that first-year students developed compatibility by partnering with a different personality type [20]. Still others have found that pair performance is uncorrelated with the skill match of pairs [25].

Perhaps guided by fears of the "Go make me a cup of tea" syndrome forewarned by Stephens and Rosenberg [33], where expert programmers do all the work, several studies that found overall positive effects for pair programming began with a process of matching students by skill level or grades (e.g., [9, 41] ). However, student feedback from another pair programming experiment indicated that pairing two experts together would not enhance their experience [7], a result that was partially mirrored in an industry experiment [1]. In addition, questions about the viability of pairing two novices together complicate this pair matching process. While some scholars have suggested that instructors should avoid pairing weak programmers together $[7,8]$, other studies contradict this advice, suggesting that pairs of novice programmers actually yield the greatest gains $[1,22]$. Lack of resolution in this area is likely due in some part to the wide variation in how skill and experience have been operationalized. Taken together, it seems that instructors wishing to implement pair programming effectively in their classrooms have much to consider but no consensus to guide their planning.

The current study explored data from a large sample of undergraduate students enrolled in introductory CS coursework to better understand how, if at all, student programming experience matters within pairs. By doing so, it sought to address several problems with the previous literature. First, pairings were randomly assigned, which means that strong causal conclusions about pair composition can be drawn. Previous research has used a wide variety of pair matching approaches, many of which may contain problems with selfselection into pairs. Second, the large sample in this study provides the necessary statistical power for identifying significant differences if they exist. Many earlier findings did not rise to the level of statistical significance due, at least in part, to small sample sizes. Third, previous studies have faced challenges in identifying appropriate measures of skill and experience; this problem is exacerbated by a tendency for more expert programmers to underestimate their ability, while more novice programmers tend to overestimate their ability [5]. In particular, earlier research has often asked students to rate their previous experience on a 0-100 scale or a Likert scale with vague response options. As an alternative, the present study used a more concrete approach by asking participants to separately rate their experience with website design, mobile apps, and several programming languages.

\section{METHOD}

\subsection{Research Design and Participants}

Participants took an introductory computer science class at the University of Iowa during the academic year from Fall 
2016 to Spring 2018. Three different introductory courses are available at the institution; the most technical is designed for computer science and statistics majors, the least technical is for humanities majors, and an intermediate course is intended for social and information science majors. The analytic sample included students who (a) were enrolled in one of the two most technical courses (virtually all students in the least technical course had little or no prior programming experience), (b) were enrolled after the fourth week of the semester (some students dropped the class in the first few weeks), and (c) had not participated in the study in a previous semester (some students took the same class multiple times or took multiple classes). Participants engaged in three different pairings throughout the course; each of these randomly assigned pairings lasted for approximately $1 / 3$ of the semester.

Students were occasionally assigned to a group of three if there was an odd number of students in the first lab section of the pairing. Only two-person pairings were included in the analyses so that a single level of partner experience could be examined. The full sample consisted of 587 undergraduates; $36 \%$ of these participants were computer science majors, $28 \%$ were female, $25 \%$ were international students, and $18 \%$ were domestic students of color.

\subsection{Measures}

Students often participated in multiple surveys and multiple paired assignments during each pairing, and the exact number and timing of these assessments varied somewhat across courses, semesters, and pairings. Therefore, to create outcome variables with the same timeframe as partner characteristics, students' responses within each pairing were averaged to create the dependent variables. As a result, students had three different measures of each outcome: one that represented the average across surveys or assignments for the first pairing, one for the second pairing, and one for the third pairing.

These outcomes included whether the student attended the lab section $(0=$ no, $1=$ yes $)$, the percentage of the assignment completed $(1=0-10 \%$, to $10=91-100 \%)$, how productive they felt within this pairing $(1=$ not at all productive, to 5 $=$ very productive), and how interested they were generally in computer science $(1=$ not at all interested, to $5=$ very interested). Participants also rated their level of agreement with several items ( $1=$ strongly disagree, to $5=$ strongly agree): understanding all concepts relevant to the assignment, putting a good amount of effort into the assignment, and being confident in the finished product. Participants also compared their own effort with that of their partner $(1=$ my partner invested more effort in this assignment, to 3 $=$ my partner invested less effort in this assignment) and provided the percentage of time in which they took the driving role, which involved sitting at the keyboard and typing out the assignment (0-100). All grades earned for lab work and homework completed during a particular pairing were averaged to indicate the level of academic performance on submitted assignments.
Computer programming experience was measured via the average of nine items that asked about prior experience with website design; programming mobile apps; and using BASIC, C/C++, Java, Javascript, Perl, Python, and Ruby. All items used a four-point scale $(1=$ none, to $4=$ a lot $)$, and the Cronbach's alpha for this index was .76. Given the right skew of the resulting distribution, the natural log of the original measure was used. A corresponding variable was created to indicate the programming experience of the partner within each pairing. Both of these measures were then standardized with a mean of zero and a standard deviation of one, and an interaction term was created by multiplying the two standardized variables. An important benefit of this recoding is that the inclusion of the interaction term did not affect the results or interpretation of the main effects (see [19]). Dummy variables were used to indicate the order of the pairing within the semester (second and third, with the initial pairing as the referent group) and the level of the introductory course $(0=$ intermediate, and $1=$ most technical).

\subsection{Analyses}

The primary outcome consisted of students' responses within a pairing, which were nested within two higher-order levels: participants (since each participant engaged in three pairings) and partners (since the partner worked on the assignment and therefore shaped the outcomes). However, participants and partners are not hierarchical to each other, since they are both students in the same class. To analyze this complex sample appropriately, cross-classified multilevel models were examined, with participants and partners crossed with each other (see $[13,31])$. The key predictors were the participant's prior computer programming experience, the partner's prior experience, and the interaction between the two. Timing during the semester and course level served as control variables. Given the experimental design of this study, we used a lenient threshold for determining statistical significance $(\mathrm{p}<.10)$; we also provide significance values at several significance cutoffs so that readers can make sense of these findings.

\section{RESULTS}

The results for all outcomes are provided in Table 1. Participants' own prior programming experience was positively and significantly associated with several outcomes: understanding concepts from the lab section, confidence in the finished assignment, feeling productive during the lab section, perceiving that their partner gave less effort than they did, and overall interest in computer science. No significant relationships were observed for the other five outcomes.

In contrast, the partner's programming experience was significantly, but negatively, related to five of the ten participant outcomes: exerting effort on the assignment, perceiving that the partner gave less effort, time spent in the driving role of pair programming, understanding concepts from the lab, and overall interest in computer science. The other five relationships were non-significant. Two of the interaction terms were 
Table 1: Results for cross-classified models predicting student outcomes in introductory computer science courses. $^{\dagger}$

\begin{tabular}{|c|c|c|c|c|c|c|c|c|c|c|}
\hline Predictor & $\begin{array}{l}\text { Exerted } \\
\text { Effort on } \\
\text { Assignment }\end{array}$ & $\begin{array}{l}\text { Partner } \\
\text { Gave Less } \\
\text { Effort }\end{array}$ & $\begin{array}{l}\text { Time in } \\
\text { Driving } \\
\text { Role }\end{array}$ & $\begin{array}{l}\text { Attended } \\
\text { Lab } \\
\text { Sections }\end{array}$ & $\begin{array}{l}\text { Percent } \\
\text { Assignment } \\
\text { Completed }\end{array}$ & $\begin{array}{l}\text { Productive } \\
\text { during Lab } \\
\text { Section }\end{array}$ & $\begin{array}{l}\text { Understand } \\
\text { Concepts } \\
\text { from Lab }\end{array}$ & $\begin{array}{l}\text { Confident } \\
\text { in Finished } \\
\text { Assignment }\end{array}$ & $\begin{array}{l}\text { Average } \\
\text { Assignment } \\
\text { Grade }\end{array}$ & $\begin{array}{l}\text { Interest in } \\
\text { Computer } \\
\text { Science }\end{array}$ \\
\hline Participant's experience & $\begin{array}{l}.048 \\
(.036)\end{array}$ & $\begin{array}{l}.041+ \\
(.023)\end{array}$ & $\begin{array}{l}1.276 \\
(.823)\end{array}$ & $\begin{array}{l}-.008 \\
(.007)\end{array}$ & $\begin{array}{l}.143 \\
(.126)\end{array}$ & $\begin{array}{l}.097^{*} \\
(.038)\end{array}$ & $\begin{array}{l}.320 * * * \\
(.045)\end{array}$ & $\begin{array}{l}.203^{* * *} \\
(.042)\end{array}$ & $\begin{array}{l}.004 \\
(.009)\end{array}$ & $\begin{array}{l}.467^{* * *} \\
(.049)\end{array}$ \\
\hline Partner's experience & $\begin{array}{l}-.050+ \\
(.029)\end{array}$ & $\begin{array}{l}-.074^{* * *} \\
(.022)\end{array}$ & $\begin{array}{l}-1.373+ \\
(.754)\end{array}$ & $\begin{array}{l}-.006 \\
(.006)\end{array}$ & $\begin{array}{l}.097 \\
(.070)\end{array}$ & $\begin{array}{l}-.009 \\
(.029)\end{array}$ & $\begin{array}{l}-.061+ \\
(.005)\end{array}$ & $\begin{array}{l}.010 \\
(.035)\end{array}$ & $\begin{array}{l}-.007 \\
(.006)\end{array}$ & $\begin{array}{l}-.088^{* *} \\
(.031)\end{array}$ \\
\hline Participant $\times$ partner & $\begin{array}{l}-.052+ \\
(.030)\end{array}$ & $\begin{array}{l}.010 \\
(.022)\end{array}$ & $\begin{array}{l}.618 \\
(.773)\end{array}$ & $\begin{array}{l}-.017^{* *} \\
(.006)\end{array}$ & $\begin{array}{l}-.045 \\
(.087)\end{array}$ & $\begin{array}{l}-.017 \\
(.033)\end{array}$ & $\begin{array}{l}-.005 \\
(.037)\end{array}$ & $\begin{array}{l}-.048 \\
(.038)\end{array}$ & $\begin{array}{l}-.004 \\
(.006)\end{array}$ & $\begin{array}{l}-.000 \\
(.032)\end{array}$ \\
\hline Second pairing & $\begin{array}{l}-.127^{*} \\
(.059)\end{array}$ & $\begin{array}{l}.083+ \\
(.048)\end{array}$ & $\begin{array}{l}1.551 \\
(1.485)\end{array}$ & $\begin{array}{l}-.002 \\
(.013)\end{array}$ & $\begin{array}{l}-.049 \\
(.156)\end{array}$ & $\begin{array}{l}.017 \\
(.062)\end{array}$ & $\begin{array}{l}-.061 \\
(.055)\end{array}$ & $\begin{array}{l}-.149+ \\
(.078)\end{array}$ & $\begin{array}{l}-.017 \\
(.014)\end{array}$ & $\begin{array}{l}-.176^{* *} \\
(.059)\end{array}$ \\
\hline Third pairing & $\begin{array}{l}-.213^{* *} \\
(.065)\end{array}$ & $\begin{array}{l}.098^{*} \\
(.047)\end{array}$ & $\begin{array}{l}3.305^{*} \\
(1.605)\end{array}$ & $\begin{array}{l}-.040^{* *} \\
(.013)\end{array}$ & $\begin{array}{l}.192 \\
(.165)\end{array}$ & $\begin{array}{l}.070 \\
(.065)\end{array}$ & $\begin{array}{l}.055 \\
(.083)\end{array}$ & $\begin{array}{l}-.101 \\
(.085)\end{array}$ & $\begin{array}{l}-.087^{* * * *} \\
(.014)\end{array}$ & $\begin{array}{l}-.277^{* * *} \\
(.059)\end{array}$ \\
\hline Most technical CS course & $\begin{array}{l}-.134+ \\
(.079)\end{array}$ & $\begin{array}{l}-.008 \\
(.050)\end{array}$ & $\begin{array}{l}1.336 \\
(1.754)\end{array}$ & $\begin{array}{l}-.012 \\
(.015)\end{array}$ & $\begin{array}{l}.715^{* *} \\
(.273)\end{array}$ & $\begin{array}{l}-.145+ \\
(.084)\end{array}$ & $\begin{array}{l}.397 * * * \\
(.098)\end{array}$ & $\begin{array}{l}-.161+ \\
(.096)\end{array}$ & $\begin{array}{l}-.090^{* * *} \\
(.019)\end{array}$ & $\begin{array}{l}-.127 \\
(.105)\end{array}$ \\
\hline
\end{tabular}

also significant, such that high levels of programming experience for both the participant and partner predicted lower participant effort on the assignment and less attendance of lab sections above and beyond the main effects. None of the prior experience variables was significantly related to average assignment grade or percent of the assignment completed.

Regarding the control variables, several outcomes declined during the third and final pairing. Specifically, students' effort on assignments, perception of effort relative to their partner, lab section attendance, average assignment grade, and interest in computer science were all lower within the third pairing than the first pairing (i.e., the referent group for the analyses). These declines over time may result from fatigue several months into the semester. The overall means for the outcomes differed across the two introductory courses in an inconsistent manner, which may be the product of receiving somewhat different pair programming assignments in those courses. Finally, supplemental analyses (not reported here) examined potential interactions between introductory course type (intermediate versus most technical) and the prior programming experience of participants and partners; these found that the primary relationships of interest did not differ significantly across the two computer science courses.

\section{DISCUSSION}

The various negative results for partners' prior experience are quite noteworthy, especially since the random assignment of pairings means that these patterns represent causal effects. Most of the significant findings pertain to the amount or allocation of effort; participants with more experienced partners generally perceive that they exerted less effort, that their partner exerted more effort than they did, and that they spent less time in the driving role. These findings are consistent with an interpretation that students may let experienced partners take the lead on the pair programming assignments and/or the experienced partner assumes the lead regardless of how involved the other partner wants to be. In some ways, this effort allocation serves a useful short-term functional role, since students with prior experience may be better equipped to complete the assignment successfully, so distributing effort accordingly may lead to a higher grade on that pair programming assignment.

However, this lower effort may not be helpful - and can sometimes backfire - in terms of other relevant outcomes. Partners' prior experience is actually unrelated to perceived productivity during the lab section, percent of the assignment completed, and confidence in the finished assignment. In fact, perhaps because of this deference within the group work, partners' experience contributes to reductions in not only participants' understanding of concepts from the lab section, but also their overall interest in computer science. Another explanation for these two patterns is that having a more experienced partner leads to reduced self-confidence among students who may perceive that they are not as well-prepared or knowledgeable as their peers. Regardless of the mechanism, these negative effects stand in stark contrast to an ideal vision of collaborative learning, in which more experienced and knowledgeable students help mentor and promote the development of other team members.

The finding that more experienced participants perceived exerting more effort than their partner provides further evidence for the explanation that effort tends to be associated with prior experience. Additional findings based on participants' prior experience likely provide further insight into this relationship. Almost by definition, students with more programming experience should have a better understanding of relevant course concepts. It follows logically that experienced students would then be more confident in their assignment by employing this prior knowledge, which may also be useful for enhancing productivity during the class period. The fact that experienced students have already engaged in relevant activities also suggests that they should generally enter the course with - and likely maintain - a greater overall interest in computer science.

The interaction terms between participant and partner experience were generally unrelated to student outcomes 
after accounting for the main effects discussed above; the two exceptions were significant, negative relationships for attending lab sections and exerting effort on the assignment. In both cases, pairings that consisted of two highly experienced members may not have needed to work as hard in order to complete the assignment successfully. Overall, the frequency of significant results for the main effects of partner experience, coupled with the rare significant findings for the interactions, suggest that partners' prior experience may be more important than pair similarity in determining student outcomes.

\section{CONCLUSION AND FUTURE WORK}

This large-scale study improves our understanding of the relationships between prior experience and pair programming outcomes through implementation of a true experimental design and use of more concrete measures of programming experience than in previous research. For instructors using pair programming, the findings presented here support recommendations that pairs be formed by matching similar skill or experience levels rather than making random assignments. The negative effects of being matched with a more experienced partner may reflect a learning environment that is less collaborative than intended. That said, more work is needed to explore the effects of novice-novice pairings and whether instructors should ethically pair students by experiential similarity, which could create disparities in short-term performance. Additionally, we hope that future research will build on the work of scholars such as Bryant [5] and [29] by using observational qualitative methods to better understand how and when experience shapes pair programming dynamics.

\section{ACKNOWLEDGMENTS}

This material is based upon work supported by the National Science Foundation under Grant No. 1611908 (AMS and NAB, CoPIs). Any opinions, findings, and conclusions or recommendations expressed in this material are those of the authors and do not necessarily reflect the views of the National Science Foundation. The authors wish to thank Professors James Cremer, Ines Curto, and Denise Szecsei as well as graduate teaching assistants Abhijeet Kharkar and Sai Kalyan Moguloju from the University of Iowa Computer Science Department for their support and assistance during the data collection portion of this study.

\section{REFERENCES}

[1] E. Arisholm, H. Gallis, T. Dyba, and D.I.K. Sjoberg. 2007. Evaluating pair programming with respect to system complexity and programmer expertise. IEEE Transactions on Software Engineering 33, 2 (Feb. 2007), 65-86. https://doi.org/10.1109/TSE. 2007.17

[2] K. Beck, M. Beedle, A. van Bennekum, A. Cockburn, W. Cunningham, M. Fowler, J. Grenning, J Highsmith, A. Hunt, R. Jeffries, J. Kern, B. Marick, R.C. Martin, S. Mellor, K. Schwaber, J. Sutherland, and D. Thomas. 2001. Manifesto for agile software development. http://www.agilemanifesto.org

[3] A. Begel and N. Nagappan. 2008. Pair programming: What's in it for me?. In Proceedings of the second ACM-IEEE international symposium on empirical software engineering and measurement ESEM08. ACM Press, Kaiserslautern, Germany, 120-128. https: //doi.org/10.1145/1414004.1414026

[4] J. Bevan, L. Werner, and C. McDowell. 2002. Guidelines for the use of pair programming in a freshman programming class. In Proceedings 15 th conference on software engineering education and training (CSEEETO2). IEEE Comput. Soc, Covington, KY, 100-107. https://doi.org/10.1109/CSEE.2002.995202

[5] S. Bryant. 2004. Double trouble: Mixing qualitative and quantitative methods in the study of eXtreme programmers. In 2004 IEEE symposium on visual languages - Human centric computing. IEEE, Rome, 55-61. https://doi.org/10.1109/VLHCC.2004.20

[6] L. Cao and P. Xu. 2005. Activity patterns of pair programming. In Proceedings of the 38th Hawaii International Conference on System Sciences HICSS05. IEEE, Big Island, HI, 88a-88a.

[7] E.A. Chaparro, A. Yuksel, P. Romero, and S. Bryant. 2005. Factors affecting the perceived effectiveness of pair programming in higher education. In Proceedings of the Psychology of Programming Interest Group (Brighton, UH). 5-18.

[8] W. Chigona and M. Pollock. 2008. Pair programming for information systems students new to programming: Students' experiences and teachers' challenges. In PICMET'08 - 2008 Portland International Conference on Management of Engineering $\&$ Technology. IEEE, Cape Town, South Africa, 1587-1594. https://doi.org/10.1109/PICMET.2008.4599777

[9] K.S. Choi, F.P. Deek, and I. Im. 2008. Exploring the underlying aspects of pair programming: The impact of personality. Information and Software Technology 50, 11 (Oct. 2008), 1114-1126. https://doi.org/10.1016/j.infsof.2007.11.002

[10] D.C Cliburn. 2003. Experiences with pair programming at a small college. Journal of computing sciences in colleges 19, 1 (2003), 20-29.

[11] T. Dyba, E. Arisholm, D.I.K. Sjoberg, J.E. Hannay, and F. Shull. 2007. Are two heads better than one? On the effectiveness of pair programming. IEEE Software 24, 6 (Nov. 2007), 12-15. https://doi.org/10.1109/MS.2007.158

[12] S. Faja. 2011. Pair programming as a team based learning activity: A review of research. Issues in information systems 12, 2 (2011), 207-216. http://iacis.org/iis/2011/207-216_AL2011_1700.pdf

[13] A. Fielding and H. Goldstein. 2006. Cross-classified and multiple membership structures in multilevel models: An introduction and review. Technical Report Research Report no. 791. University of Birmingham, Birmingham, UK.

[14] B. Hanks. 2006. Student attitudes toward pair programming. ACM SIGCSE Bulletin 38, 3, 113-117.

[15] B. Hanks, S. Fitzgerald, R. McCauley, L. Murphy, and C. Zander. 2011. Pair programming in education: A literature review. Computer Science Education 21, 2 (2011), 135-173.

[16] B. Hanks, C. McDowell, D. Draper, and M. Krnjajic. 2004. Program quality with pair programming in CS. In Proceedings of the 9th annual SIGCSE conference on innovation and technology computer science education. Leeds, UK, 176-180.

[17] J.E. Hannay, E. Arisholm, H. Engvik, and D.I.K. Sjoberg. 2010. Effects of personality on pair programming. IEEE Transactions on Software Engineering 36, 1 (Jan. 2010), 61-80. https://doi. org/10.1109/TSE.2009.41

[18] E.V. Howard. 2006. Attitudes on using pair-programming. Journal of Educational Technology Systems 35, 1 (Sept. 2006), 89-103. https://doi.org/10.2190/5K87-58W8-G07M-2811

[19] J. Jaccard and R. Turrisi. 2003. Interaction effects in multiple regression (2nd ed.). Sage Publications, Thousand Oaks, CA.

[20] N. Katira, L. Williams, E. Wiebe, C. Miller, S. Balik, and E. Gehringer. 2004. On understanding compatibility of student pair programmers. In Proceedings of the 35th SIGCSE technical symposium on computer science education. Norfolk, VA, 7-11.

[21] L. Layman. 2006. Changing students' perceptions: An analysis of the supplementary benefits of collaborative software development. In Proceedings of the 19th Conference Software Engineering Education and Training. IEEE, Turtle Bay, HI, 159-166. https: //doi.org/10.1109/cseet.2006.10

[22] K.M. Lui and K.C.C. Chan. 2006. Pair programming productivity: Novice-novice vs. expert-expert. International Journal of Human-Computer Studies 64, 9 (Sept. 2006), 915-925. https://doi.org/10.1016/j.ijhcs.2006.04.010

[23] G. Melnik and F. Maurer. 2005. A cross-program investigation of students' perceptions of agile methods. In Proceedings of the 27th International Conference on Software Engineering ICSE05. IEEE, St. Louis, MO, 481-488. 
[24] E. Mendes, L. Al-Fakhri, and A. Luxton-Reilly. 2006. A replicated experiment of pair-programming in a 2nd-year software development and design computer science course. ACM SIGCSE Bulletin 38, 3 (2006), 108-112.

[25] M.M. Muller and F. Padberg. 2004. An empirical study about the feelgood factor in pair programming. In 10th International Sym posium on Software Metrics, 2004. Proceedings. IEEE, Chicago, IL, 151-158. https://doi.org/10.1109/METRIC.2004.1357899

[26] N. Nagappan, L. Williams, M. Ferzli, E. Wiebe, K. Yang, C Miller, and S. Balik. 2003. Improving the CS1 experience with pair programming. ACM SIGCSE Bulletin 35, 1 (2003), 359-362.

[27] J.T. Nosek. 1998. The case for collaborative programming. Commun. ACM 41, 3 (March 1998), 105-108. https://doi.org/10. $1145 / 272287.272333$

[28] Y. Oya and K. Uchida. 2013. Practical consideration of pair problem solving in computer literacy education. IAFOR Journal of Education 1, 1 (May 2013), 103-120. https://doi.org/10. 22492/ije.1.1.04

[29] L. Plonka, H. Sharp, and J. van der Linden. 2012. Disengagement in pair programming: Does it matter?. In 201234 th International Conference on Software Engineering (ICSE). IEEE, Zurich, 496506. https://doi.org/10.1109/ICSE.2012.6227166

[30] L. Plonka, H. Sharp, J. van der Linden, and Y. Dittrich. 2015 Knowledge transfer in pair programming: An in-depth analysis. International Journal of Human-Computer Studies 73 (Jan. 2015), 66-78. https://doi.org/10.1016/j.ijhcs.2014.09.001

[31] S.W. Raudenbush and A.S. Bryk. 2002. Hierarchical linear mod els: Applications and data analysis methods (2nd ed.). Sage Publications, Thousand Oaks, CA.

[32] N. Salleh, E. Mendes, and J. Grundy. 2011. Empirical studies of pair programming for CS/SE teaching in higher education: A systematic literature review. IEEE Transactions on Software Engineering 37, 4 (July 2011), 509-525. https://doi.org/10.1109/ TSE.2010.59

[33] M. Stephens and D. Rosenberg. 2003. Extreme programming refactored: The case against XP. Apress, Berkeley, CA.
[34] L. Thomas, M. Ratcliffe, and A. Robertson. 2003. Code warriors and code-a-phobes: A study in attitude and pair programming. ACM SIGCSE Bulletin 35, 1 (2003), 363-367.

[35] K. Umapathy and A.D. Ritzhaupt. 2017. A meta-analysis of pairprogramming in computer programming courses: Implications for educational practice. ACM Transactions on Computing Education 17, 4 (Aug. 2017), 1-13. https://doi.org/10.1145/ 2996201

[36] T. Van Toll III, R. Lee, and T. Ahlswede. 2007. Evaluating the usefulness of pair programming in a classroom setting. In 6th IEEE/ACIS International Conference on Computer and Information Science (ICIS 2007). IEEE, Melbourne, Australia, 302-308. https://doi.org/10.1109/ICIS.2007.96

[37] E.N. Wiebe, L. Williams, J. Petlick, N. Nagappan, S. Balik, C. Miller, and M. Ferzli. 2003. Pair programming in introductory programming labs. In Proceedings Submitted to the American Society for Engineering Education Annual Conference and Exposition (Washington, DC).

[38] L. Williams and R. Kessler. 2002. Pair programming illuminated. Addison-Wesley, Boston, MA.

[39] L. Williams, L. Layman, J. Osborne, and N. Katira. 2006. Examining the compatibility of student pair programmers. In AGILE 2006 (AGILE'06). IEEE, Minneapolis, MN, 411-420. https://doi.org/10.1109/AGILE.2006.25

[40] L. Williams, C. McDowell, N. Nagappan, J. Fernald, and L. Werner. 2003. Building pair programming knowledge through a family of experiments. In 2003 International Symposium on Empirical Software Engineering, 2003. ISESE 2003. Proceedings. IEEE Comput. Soc, Rome, Italy, 143-152. https: //doi.org/10.1109/ISESE.2003.1237973

[41] N.Z. Zacharis. 2011. Measuring the effects of virtual pair programming in an introductory programming java course. IEEE Transactions on Education 54, 1 (Feb. 2011), 168-170. https: //doi.org/10.1109/TE.2010.2048328 